\title{
2-methylfuran Oxidation in the Absence and Presence of NO
}

\author{
Katiuska Alexandrino ${ }^{1}$ • Ángela Millera ${ }^{1}$. \\ Rafael Bilbao $^{1}$ - María U. Alzueta ${ }^{1}$ (D)
}

Received: 3 March 2015 / Accepted: 27 July 2015

(C) Springer Science+Business Media Dordrecht 2015

\begin{abstract}
MF) has become of interest as biofuel because of its properties and the improvement in its production method, and also because it is an important intermediate in the conversion of 2,5-dimethylfuran. In this research, an experimental and kinetic modelling study of the oxidation of 2-MF in the absence and presence of NO has been performed in an atmospheric pressure laboratory installation. The experiments were performed in a flow reactor and covered the temperature range from 800 to $1400 \mathrm{~K}$, for mixtures from very fuel-rich to very fuel-lean, highly diluted in nitrogen. The inlet 2-MF concentration was $100 \mathrm{ppm}$. In the experiments in the presence of NO, the inlet NO concentration was $900 \mathrm{ppm}$. An interpretation of the experimental results was performed through a gas-phase chemical kinetic model. A reasonable agreement between the experimental trends and the modelling data is obtained. The results of the concentration profile of 2-MF as a function of temperature indicate that, both in the absence and in the presence of $\mathrm{NO}$, the onset of 2-MF consumption is shifted to lower temperatures only under fuel-lean and very fuel-lean conditions. Furthermore, under these conditions the presence of NO also shifts the onset of 2-MF consumption to lower temperatures. The effect of the 2-MF presence on the NO reduction varies with the oxygen concentration. It is seen that under very fuel-rich and stoichiometric conditions NO is reduced basically by reburn reactions, while under fuel-lean and very fuel-lean conditions, the $\mathrm{NO}-\mathrm{NO}_{2}$ interconversion appears to be dominant.
\end{abstract}

Keywords 2-methylfuran · Oxidation · Nitric oxide $\cdot$ Flow reactor $\cdot$ Kinetic model

Electronic supplementary material The online version of this article

(doi:10.1007/s10494-015-9635-z) contains supplementary material, which is available to authorized users.

María U. Alzueta

uxue@unizar.es

1 Aragón Institute of Engineering Research (I3A), Department of Chemical and Environmental Engineering, University of Zaragoza, Río Ebro Campus. 50018 Zaragoza, Spain 


\section{Introduction}

Furan derivatives have recently gained a special interest as it is believed they may be a good alternative as new biofuels. 2,5-dimethylfuran (2,5-DMF, $\mathrm{C}_{6} \mathrm{H}_{8} \mathrm{O}$ ) and 2-methylfuran (2$\mathrm{MF}, \mathrm{C}_{5} \mathrm{H}_{6} \mathrm{O}$ ) have an special importance due to the improvement in their production method through the conversion of fructose, glucose, and even cellulose [1-3]. Moreover, 2-MF is a product formed in both the pyrolysis and oxidation of 2,5-DMF. This work is focused on 2-MF. Research on 2,5-DMF oxidation, and its interaction with $\mathrm{NO}$ can be found in our previous publications $[4,5]$.

2-MF has attractive properties as biofuel, it has even several advantages over ethanol, the currently more used biofuel. For example, its higher rate of vaporization and higher combustion stability make it more robust to cold engine start than ethanol [6]. In this way, the potential of 2-MF as biofuel has been already investigated in spark ignition (SI) engines $[6,7]$. Wang et al. [8] studied the combustion characteristics and emissions of 2-MF compared to 2,5-DMF, gasoline and ethanol in a direct injection spark ignition (DISI) engine. They found that the overall regulated emissions ( $\mathrm{CO}, \mathrm{HC}$ (unburned hydrocarbons), $\mathrm{NO}_{\mathrm{x}}$ and PM (particulate matter)) from 2-MF are comparable to the other tested fuels, whereas the aldehyde emission is much lower than the obtained from gasoline and ethanol. To our knowledge, 2-MF has not yet been studied in diesel vehicles.

As a biofuel candidate, a better understanding of the combustion of 2-MF is necessary. Grela et al. [9] studied the decomposition of furan, 2-MF and 2,5-DMF in a heated flow reactor operating at very low pressures (1 mtorr) and temperatures of 1050-1270 K. Lifshitz et al. [10] studied the decomposition of 2-MF behind shock waves in a pressurized driver single pulse shock tube over the temperature range 1100-1400 K. More recently, the combustion intermediates in 2-MF premixed flames [11], laminar burning characteristics [12, 13], ignition delays in shock-tube [14-17] and computational study of the combustion and atmospheric decomposition of 2-MF [18], have been studied. Somers et al. [19] conducted an experimental and modelling ignition delay time study for 2-MF for different equivalence ratios $(0.5,1$, and 2$)$ in the $1200-1800 \mathrm{~K}$ temperature range, and laminar burning velocities were also determined for mixtures of 2-MF at equivalence ratios of 0.55-1.65 in the 298$398 \mathrm{~K}$ temperature range. The authors used these experimental results to validate a chemical kinetic mechanism which describes the 2-MF oxidation. In this mechanism, Quantum-RiceRamsperger-Kassel (QRRK) theory with a Modified Strong Collision (MSC) approach was utilized to account for the influence of pressure on reaction rate constants. The reactions of hydrogen atoms with the fuel were highlighted as important. Specifically, through sensitivity analysis, they found that the $\mathrm{H}$-abstraction by hydrogen atoms promotes reactivity while the $\mathrm{H}$-addition at the $\mathrm{C} 2$ site of 2-MF inhibits it. This model has been used in recent studies addressing the ignition phenomena of 2-MF $[14,15]$. Continuing with this work, Somers et al. [20] described, in a more complete way, the ab initio calculations in which their original model [19] was based. Here the authors used more rigorous Rice-Ramsperger-KasselMarcus (RRKM) theory calculations coupled with an energy grained Master Equation (ME) solution to account for the influence of pressure on reaction rate constants. The new kinetic mechanism developed was validated with different experimental results from literature (e.g. $[10,14])$

A series of three papers jointly consider the combustion chemistry of furan [21] and its alkylated derivatives: 2-MF [22] and 2,5-DMF [23], under premixed low-pressure flame conditions using molecular-beam mass spectrometry and gas chromatography. The reaction mechanism used in this series of papers [21-23] is based on a previous mechanism 
by Sirjean et al. [24] which was developed to describe the combustion of 2,5-DMF. This mechanism [24] includes the furan oxidation sub-mechanism of Tian et al. [25] and a 2MF oxidation sub-mechanism based on analogies with 2,5-DMF and furan reactions. In the above mentioned series of fuel studies [21-23], some of the reactions or rate parameters of the furan and 2-MF sub-mechanisms in the Sirjean et al. [24] model were updated or replaced to improve the simulation of some intermediates, while the 2,5-DMF submechanism was not changed. Through this modified mechanism [21-23], the authors found that the $\mathrm{H}$-addition pathways played an important role in the 2-MF consumption and species formation. Continuing with the work of Tran et al. [22], Moshammer et al. [26] studied the premixed combustion of 2-MF by measuring oxygenated and hydrocarbon intermediates, using synchrotron-generated vacuum-ultraviolet photons in combination with a high-resolution mass spectrometer. The experimental data are compared with modelling calculations using the combustion chemistry model employed in the series of three papers [21-23] with success. However, many experimentally newly detected species such as fulvene, $\mathrm{C}_{5} \mathrm{H}_{4}$ isomers (pentatetraene, ethynylallene, 1,3-pentadiyne, and 1,4-pentadiyne), $\mathrm{C}_{3} \mathrm{H}_{8} \mathrm{O}$ isomers (1- and 2-propanol and ethyl methyl ether), vinyl ketene $\left(\mathrm{CH}_{2} \mathrm{CHCHCO}\right)$, etc., are not included in the model from Tran et al. [22], thus the results of these species could not be compared with modelling results.

It is important to study the oxidation of 2-MF, but also to study the effect of the presence of typical contaminants existing in the combustion chamber of engines, as for example NO, on the oxidation of 2-MF, as well as to study if the presence of 2-MF is able to reduce the concentration of these contaminants, in this case NO. Thus, in this work we have investigated the 2-MF oxidation in the absence and in the presence of NO. The inlet 2-MF and NO concentrations were 100 and $900 \mathrm{ppm}$, respectively, which correspond to an inlet $\mathrm{C} / \mathrm{N}$ ratio of 0.56. All the experiments were carried out in a quartz flow reactor at atmospheric pressure, in the temperature range $800-1400 \mathrm{~K}$, for different air excess ratio values $(\lambda=0.3,1,5$ and 50), which is defined as the inlet oxygen concentration divided by the oxygen necessary for complete combustion. Thus, the influence of the oxygen concentration on the oxidation of 2-MF and on the NO consumption can be evaluated. The main reactions involved in the oxidation of 2-MF in the presence and absence of NO, as well as, in the NO consumption, have been identified by interpreting the experimental results in terms of a detailed chemical kinetic model. With this paper, in addition to show the influence of the presence of NO on the 2-MF oxidation and show if 2-MF is capable to reduce the NO concentration under different oxidizing conditions, we provide experimental data that can be used to further refine chemical kinetic models for 2-MF.

\section{Experimental Approach}

Experiments were performed in an atmospheric pressure facility previously used and described [e.g. 27, 28]. Briefly, the quartz flow reactor employed, with an inner diameter of $8.7 \mathrm{~mm}$ and a reaction zone of $200 \mathrm{~mm}$ in length, was designed for obtaining plug flow conditions [29]. This reactor is placed in a three-zone electrically heated furnace. The flat temperature profile is within $\pm 10 \mathrm{~K}$. The gases are led to the reactor through calibrated mass flow-controllers in four separate streams: a main flow, which contains water vapor and nitrogen, and three injector tubes, through which 2-MF, $\mathrm{O}_{2}$ and $\mathrm{NO}$ (this last when applicable) are supplied. Water vapor is injected saturating a $\mathrm{N}_{2}$ stream through a water bubbler. $\mathrm{N}_{2}$ is used to close the balance, i.e, to achieve a total flow rate of $1000 \mathrm{~mL}(\mathrm{STP}) / \mathrm{min}$. To achieve 
a well-defined reactor volume, the main flow and the three injector flows are heated separately and mixed in cross-flow at the reactor inlet. The residence time, for the given total flow rate and a constant volume of the reaction zone is, $\mathrm{t}_{\mathrm{r}}(\mathrm{s})=195 / \mathrm{T}(\mathrm{K})$.

The gas outlet stream is cooled using cold air, and passes through a condenser and filter for conditioning. The concentration of 2-MF, NO and some products, including some nitrogen species, was analyzed by using an Agilent 3000A microchromatograph (2-MF, $\mathrm{H}_{2}, \mathrm{CO}$, $\mathrm{CO}_{2}, \mathrm{C}_{2} \mathrm{H}_{4}, \mathrm{C}_{2} \mathrm{H}_{2}$ ), an $\mathrm{ABB}$ continuous Uras $14 \mathrm{IR}$ for $\mathrm{CO} / \mathrm{CO}_{2}$ and Uras 26 IR for NO, and Mattson Fourier Transform Infrared (FTIR) spectrometer (NO, $\mathrm{NO}_{2}, \mathrm{~N}_{2} \mathrm{O}, \mathrm{HCN}$ and $\mathrm{NH}_{3}$ ). The uncertainty of the concentration measurements is estimated as $\pm 5 \%$, except for the FTIR spectrometer, which is estimated as $\pm 10 \%$.

The experimental specifications are gathered in Table 1 . The oxygen concentration is varied for air excess ratio values ranging from 0.3 to $50.900 \mathrm{ppm}$ of $\mathrm{NO}$ is used in the experiments of 2-MF oxidation in the presence of $\mathrm{NO}$, corresponding to an inlet $\mathrm{C} / \mathrm{N}$ ratio value of 0.56 , which is similar to previous studies in our group [e.g. 28], and this NO concentration can be representative of real combustion processes [30, 31]. All the experiments are performed under very diluted conditions to prevent heat release, so an isothermal reaction zone is guaranteed.

\section{Kinetic Modelling}

The mechanism used as starting point is that compiled and used in our previous studies on the 2,5-DMF oxidation in the presence and absence of $\mathrm{NO}[4,5]$. That mechanism has been progressively develop in our group, and includes the conversion of $\mathrm{C}_{1} / \mathrm{C}_{2}$ hydrocarbons and their interaction with NO, the conversion of different oxygenated hydrocarbons, as well as other compounds of interest [27, 28, 32-36]. To this mechanism, the sub-mechanisms for furan, 2,5-DMF, 2-MF, and other intermediates from the work of Sirjean et al. [24] were added and used in the previous works $[4,5]$.

As a first stage, and in order to evaluate different reactions sub-mechanisms available in the literature for 2-MF conversion, in the present work three different 2-MF sub-mechanisms were incorporated separately in our base mechanism, resulting in: 1)

Table 1 Experimental conditions: $\left[\mathrm{C}_{5} \mathrm{H}_{6} \mathrm{O}\right]=100 \mathrm{ppm}, \mathrm{T}=800-1400 \mathrm{~K}$, Flow rate $=1000 \mathrm{~mL}(\mathrm{STP}) / \mathrm{min}$, and $\mathrm{t}_{\mathrm{r}}(\mathrm{s})=195 / \mathrm{T}(\mathrm{K}) . \mathrm{N}_{2}$ is used to close the balance

\begin{tabular}{llllll}
\hline Set & $\mathrm{O}_{2}(\mathrm{ppm})$ & $\lambda$ & $\mathrm{NO}(\mathrm{ppm})$ & $\mathrm{H}_{2} \mathrm{O}(\mathrm{ppm})$ & C/N Molar ratio \\
\hline 1 & 180 & 0.3 & 0 & 6343 & \\
2 & 180 & 0.3 & 900 & 6343 & 0.56 \\
3 & 600 & 1 & 0 & 8108 & \\
4 & 600 & 1 & 900 & 8108 & 0.56 \\
5 & 3000 & 5 & 0 & 6343 & \\
6 & 3000 & 5 & 900 & 6343 & 0.56 \\
7 & 30000 & 50 & 0 & 6748 & 0.56 \\
8 & 30000 & 50 & 900 & 7629 & \\
\hline
\end{tabular}


mechanism 1, incorporates in the base mechanism developed by our group the 2-MF submechanism by Sirjean et al. [24]; 2) mechanism 2, includes the 2-MF sub-mechanism by Tran et al. [22], which is the same sub-mechanism used in the mechanism 1, in which the authors, changed some kinetic parameters for certain reactions in order to improve lowpressure premixed flames results. The authors also add to this sub-mechanism an H-atom addition reaction on the $\mathrm{C} 2$ site of 2-MF, yielding 1,3-butadiene $\left(\mathrm{CH}_{2} \mathrm{CHCHCH}_{2}\right)$ and the HCO radicals. Finally, 3) mechanism 3 incorporates to the base mechanism developed in our group, the 2-MF sub-mechanism from Somers et al. [20], in which an ab initio study was carried out to calculate kinetic parameters for the 2-MF sub-mechanism, and accounts for the influence of pressure on reaction rate constants. The SENKIN computer code from the CHEMKIN package [37] was used to simulate the experimental data. The sensitivity analysis was performed using the CHEMKIN-PRO package [38].

Mechanisms 1, 2, and 3 have been used to simulate the present experimental results, and the comparison of some selected results is shown here in Figs. 1, 2, 3, whereas other results can be seen in Figs. S1-S7 in Online Resource.

In Figs. 1, 2, 3, concentration profiles of 2-MF, $\mathrm{CO}$ and $\mathrm{CO}_{2}$, as a function of temperature, obtained in the 2-MF oxidation in the absence of $\mathrm{NO}$ for $\lambda=0.3,5$, and 50 , are compared with modelling calculations. Figure 1 reveals that the three mechanisms capture the 2-MF consumption under very fuel-rich conditions $(\lambda=0.3)$ with good accuracy. Also the three mechanisms follow the same trend for the $\mathrm{CO}$ and $\mathrm{CO}_{2}$ formation. However, none of them fits well the experimental data. This last observation is also applied to the concentration profiles of $\mathrm{H}_{2}, \mathrm{C}_{2} \mathrm{H}_{4}$ and $\mathrm{C}_{2} \mathrm{H}_{2}$, which can be observed in Fig. S1 in Online Resource. With regard to stoichiometric conditions $(\lambda=1)$ in the absence of NO, which comparison between experimental results and modelling calculations can be observed in Fig. S2, the three models fit well the 2-MF, $\mathrm{CO}$, and $\mathrm{CO}_{2}$ experimental results. However, the three mechanisms overestimate the $\mathrm{H}_{2}$ concentration values. The observations found for $\lambda=0.3$ and 1 in the absence of NO can be extended to the case of the 2-MF oxidation in the presence of NO (Figs. S3 and S4).

Figure 2 shows that, for the 2-MF oxidation under fuel-lean conditions $(\lambda=5)$ in the absence of NO, the calculations of mechanisms 2 and 3 are closer to the experimental results than the calculations of mechanism 1 , with a slightly better fit by the mechanism 3 . Nevertheless, in the presence of $\mathrm{NO}$, there is a poor fit to the experimental data by any of the three mechanisms (Fig. S5).

Comparing the experimental results obtained in the 2-MF oxidation under very fuellean conditions $(\lambda=50)$ in the absence of NO with the modelling calculations, Fig. 3 indicates that, in general, the mechanisms 1 and 2 present very close results and fit better with the experimental data than the mechanism 3, although this last mechanism fits better the experimental results when the NO is present (Fig. S6).

In Fig. S7, the performance of the different mechanisms adjusting to the experimental results of the NO concentration can also be observed. In general, the three mechanisms have the same performance, but for very fuel-lean conditions the mechanism 3 fits better the experimental results.

Taking into account the results obtained, we have chosen mechanism 3 to analyze the experimental results in the rest of the manuscript. As mentioned previously, the 2-MF conversion sub-mechanism by Somers et al. [20] has been validated with different experimental data from literature covering shock tube [10,14] and premixed flames [22] experiments. 

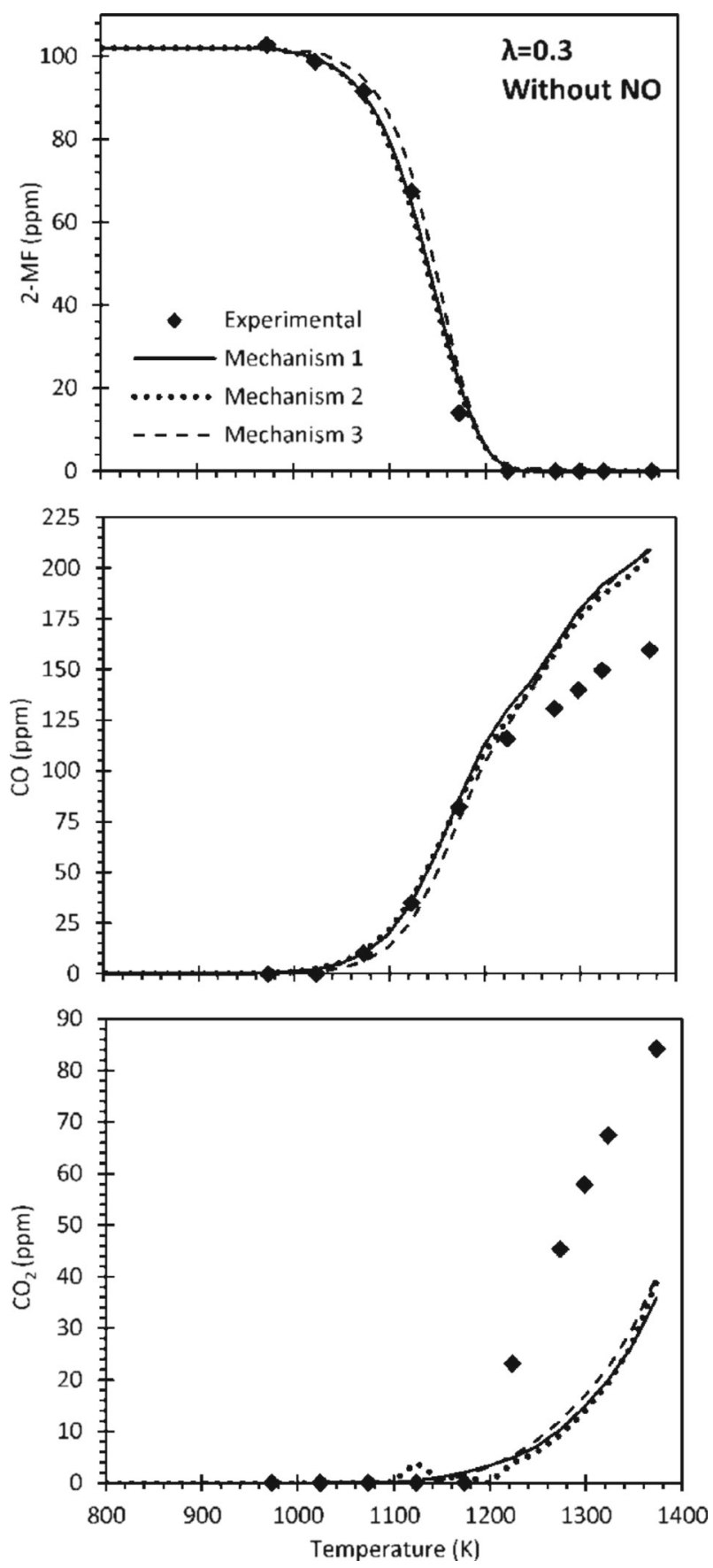

Fig. 1 Concentration profiles of 2-MF, $\mathrm{CO}$, and $\mathrm{CO}_{2}$, as a function of temperature, in the 2-MF oxidation in the absence of NO for $\lambda=0.3$, at atmospheric pressure. Symbols: experimental results. Solid line: mechanism 1, dotted line: mechanism 2, dashed line: mechanism 3 

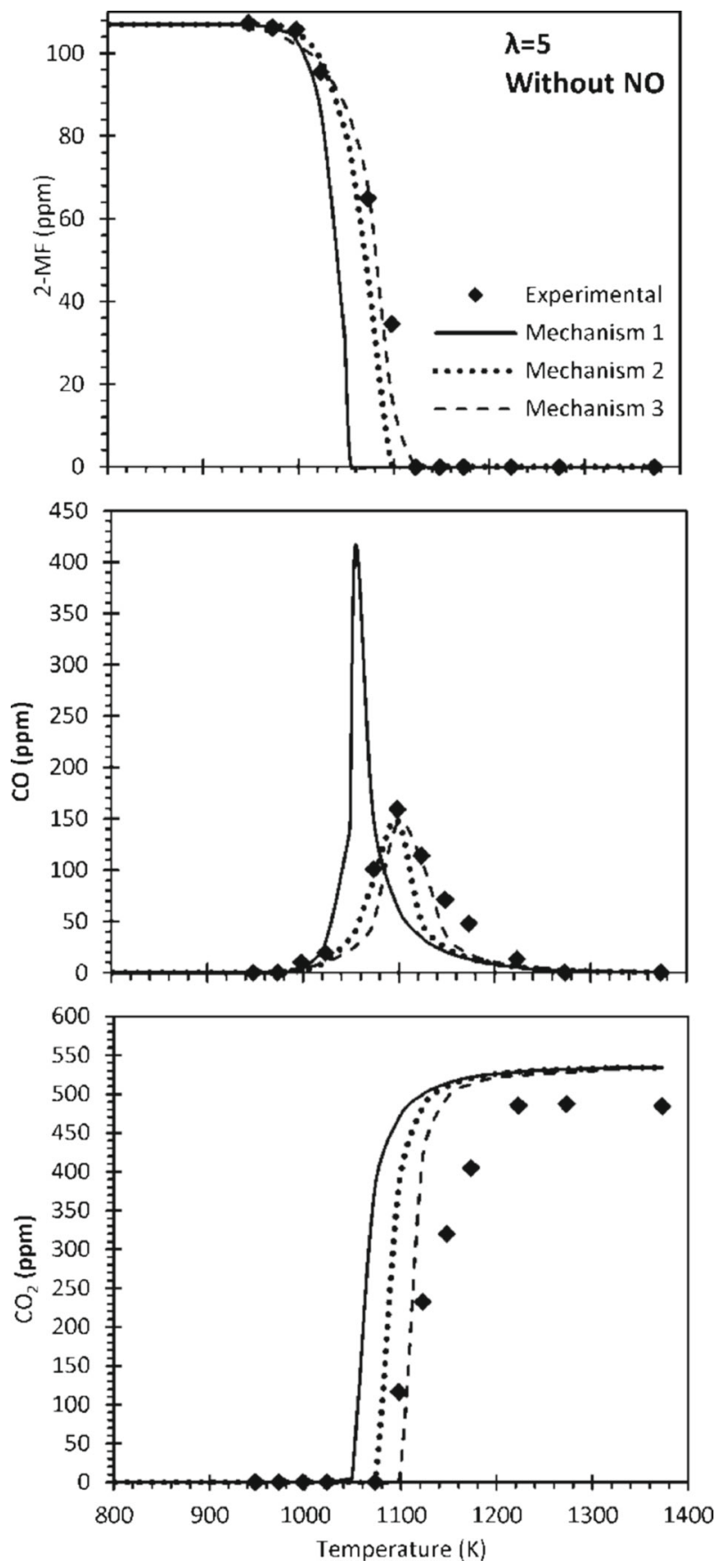

Fig. 2 Concentration profiles of 2-MF, $\mathrm{CO}$, and $\mathrm{CO}_{2}$, as a function of temperature, in the 2-MF oxidation in the absence of NO for $\lambda=5$, at atmospheric pressure. Symbols: experimental results. Solid line: mechanism 1, dotted line: mechanism 2, dashed line: mechanism 3 

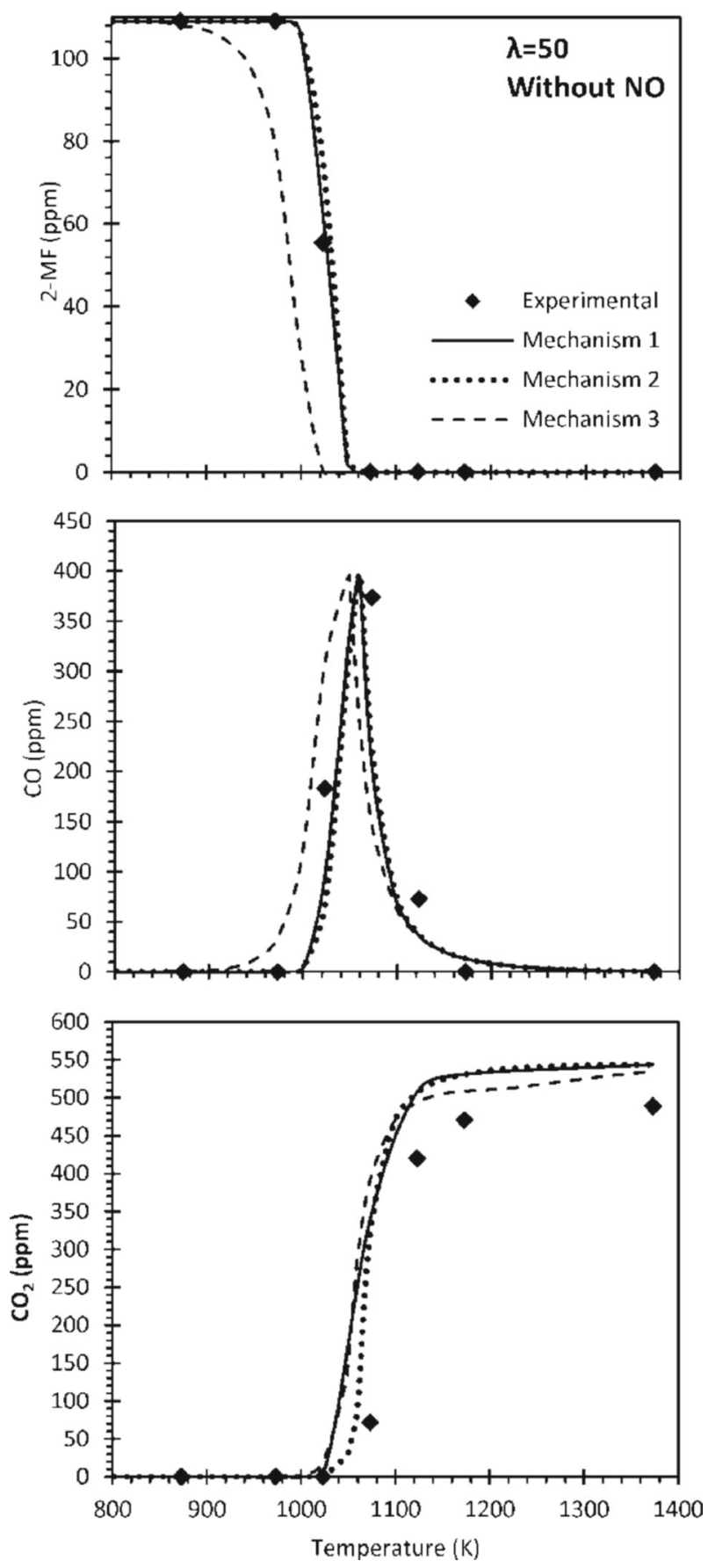

Fig. 3 Concentration profiles of 2-MF, $\mathrm{CO}$, and $\mathrm{CO}_{2}$, as a function of temperature, in the 2-MF oxidation in the absence of NO for $\lambda=50$, at atmospheric pressure. Symbols: experimental results. Solid line: mechanism 1, dotted line: mechanism 2, dashed line: mechanism 3 


\section{Results and Discussion}

Experiments of 2-MF oxidation in the absence and presence of NO have been performed in a flow reactor. In this way, the influence of the oxygen concentration and the presence of $\mathrm{NO}$ on the 2-MF oxidation, as well as, the 2-MF capacity to reduce the NO concentration for different oxygen concentrations, have been studied. A detailed kinetic model, including the mechanism progressively develop in our group, together with the reaction sub-mechanism for 2-MF by Somers et al. [20] has been selected to simulate the experimental results. The main reaction pathways of 2-MF and NO consumption under the different conditions studied are identified through modelling calculations.

Figures 4 and 5 show experimental data and modelling predictions for the 2-MF oxidation in the absence and presence of $\mathrm{NO}$ as a function of temperature, for the different $\lambda$ values studied, ranging from 0.3 to 50 . The figures include concentration results of 2-MF and $\mathrm{H}_{2}$ (left part of the figures), the latter when applicable, and of $\mathrm{CO}$ and $\mathrm{CO}_{2}$ (right part of the figures). As discussed in the previous section, in general, the model agrees well with the experimental data obtained. However, some discrepancies between experimental results and modelling calculations are found, with the major discrepancies for $\lambda=5$ in the presence of NO, and for $\lambda=50$ in the absence of NO (Fig. 5).

Regarding the influence of oxygen concentration on the 2-MF consumption, it is observed that under very fuel-rich $(\lambda=0.3)$ and stoichiometric conditions $(\lambda=1)$, and both in the absence and in the presence of NO (Fig. 4), the oxygen concentration does not influence the onset of 2-MF consumption, thus 2-MF begins to be consumed approximately at
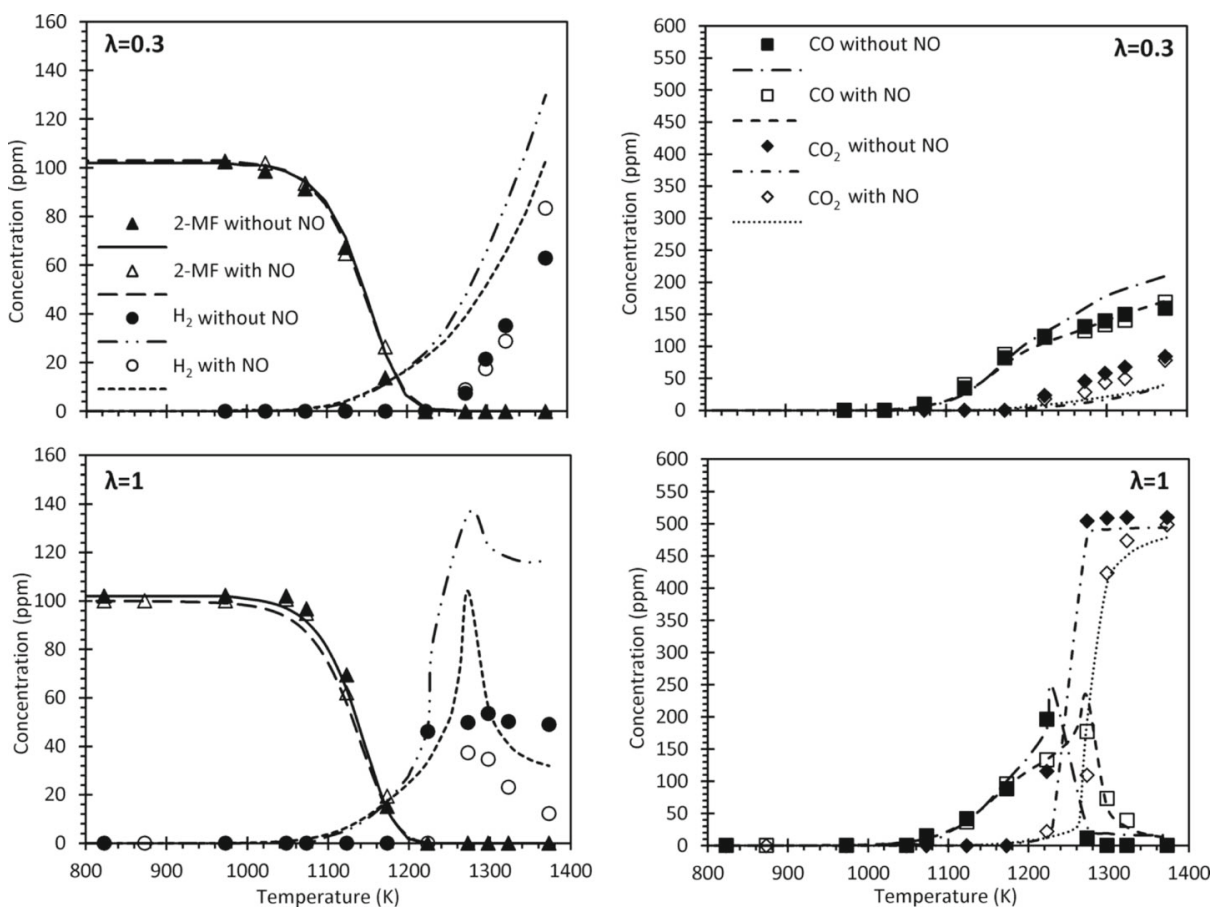

Fig. 4 Concentration profiles of the major species, as a function of temperature, in the 2-MF oxidation for $\lambda=0.3$ and 1 , at atmospheric pressure. Experimental data (symbols) and modelling predictions (lines) 

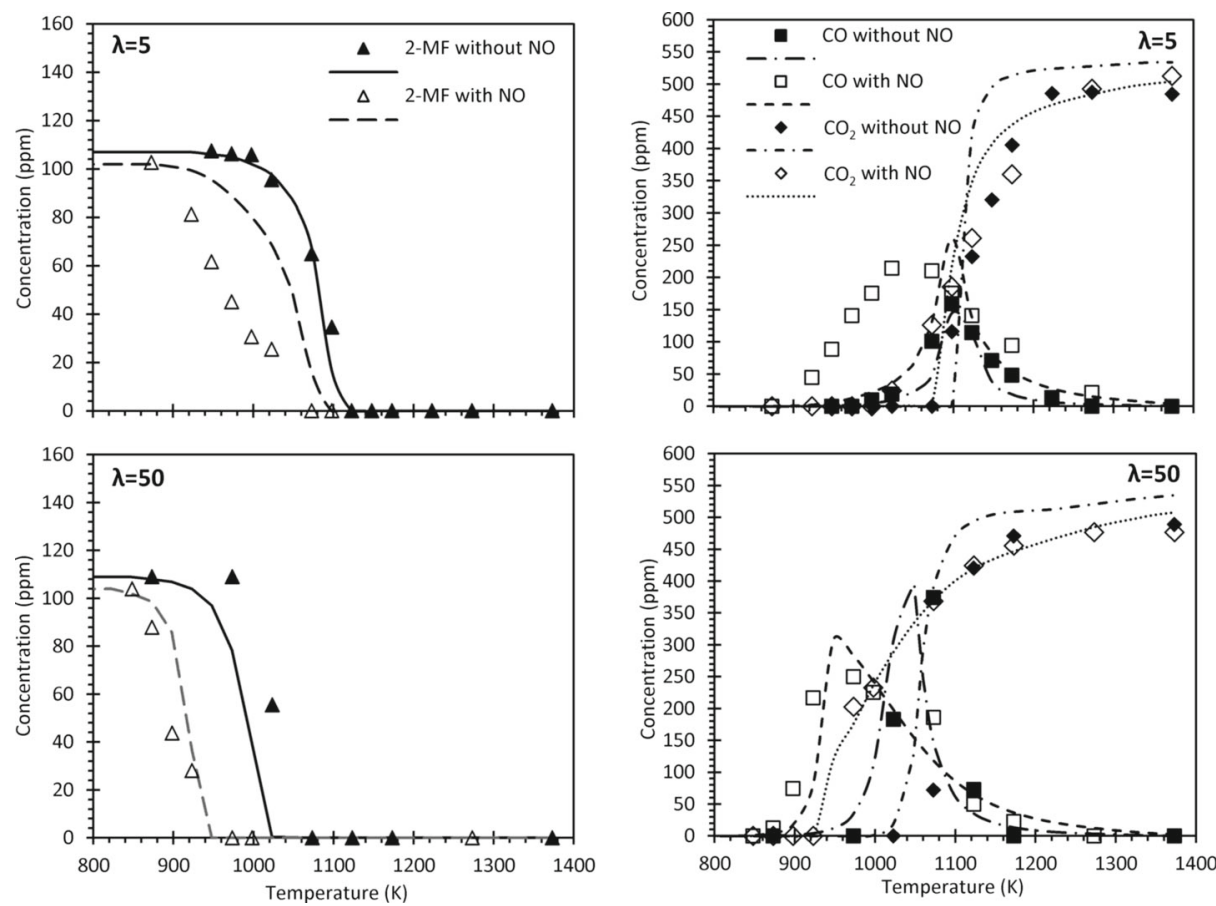

Fig. 5 Concentration profiles of the major species, as a function of temperature, in the 2-MF oxidation for $\lambda=5$ and 50, at atmospheric pressure. Experimental data (symbols) and modelling predictions (lines)

$1050 \mathrm{~K}$. However, under fuel-lean $(\lambda=5)$ and very fuel-lean $(\lambda=50)$ conditions (Fig. 5), and both in the absence and in the presence of NO, the onset of 2-MF consumption is shifted toward lower temperatures with the increasing of the oxygen concentration.

The concentration profile of 2-MF is also influenced by the presence of $\mathrm{NO}$ for $\lambda=5$ and 50 (Fig. 5). In this way, the onset of 2-MF consumption is shifted to lower temperatures in the presence of $\mathrm{NO}$, as it was observed earlier for other oxygenated compounds $[33,34,36]$. It can be due to the fact that the formation of $\mathrm{OH}$ radicals is promoted under these conditions, which will be analyzed later. On the other hand, for $\lambda=0.3$ and 1 (Fig. 4) no appreciable influence of the NO presence on the onset of 2-MF consumption can be observed. It could be attributed to the fact that under very fuel-rich and stoichiometric conditions, the thermal decomposition of 2-MF is a very important path for its consumption.

The onset for 2-MF consumption is accompanied by the formation of $\mathrm{H}_{2}$ and $\mathrm{CO} . \mathrm{H}_{2}$ is formed only under very fuel-rich and stoichiometric conditions (Fig. 4). For both conditions, the model overestimates the $\mathrm{H}_{2}$ concentration and it is observed that $\mathrm{NO}$ acts to diminish the $\mathrm{H}_{2}$ formation with the increasing of temperature. For $\lambda=0.3$, the $\mathrm{H}_{2}$ concentration increases with the increase of temperature, while for $\lambda=1$, a maximum in the $\mathrm{H}_{2}$ concentration is reached. In this case, $\mathrm{H}_{2}$ is consumed to give water and $\mathrm{H}$ radicals, through the reaction (1).

$$
\mathrm{OH}+\mathrm{H}_{2} \leftrightarrows \mathrm{H}_{2} \mathrm{O}+\mathrm{H}
$$

$\mathrm{CO}$ is formed for all the $\lambda$ values studied, and, except for $\lambda=0.3$, a maximum in the concentration profile of $\mathrm{CO}$ is reached, which is shifted to lower temperatures as the oxygen concentration increases (Figs. 4 and 5). For $\lambda=0.3$ and 1 (Fig. 4), the presence of NO does 
not influence the onset of formation of $\mathrm{CO}$, but influences the $\mathrm{CO}$ concentration formed at the higher temperatures studied. According to simulations, at intermediate temperatures (when still the influence of NO is not observed), and both in the absence and in the presence of $\mathrm{NO}, \mathrm{CO}$ is formed through the following reactions:

$$
\begin{aligned}
\mathrm{CH}_{2} \mathrm{CHCHCHCO} & \rightleftarrows \mathrm{CHCHCHCH}_{2}+\mathrm{CO} \\
\mathrm{CH}_{3} \mathrm{CHCCHCHO} & \rightleftarrows \mathrm{CHCCH}_{2} \mathrm{CH}_{3}+\mathrm{CO} \\
\mathrm{CH}_{3} \mathrm{CO}(+\mathrm{M}) & \rightleftarrows \mathrm{CH}_{3}+\mathrm{CO}(+\mathrm{M}) \\
\mathrm{HCO}(+\mathrm{M}) & \rightleftarrows \mathrm{H}+\mathrm{CO}(+\mathrm{M})
\end{aligned}
$$

However, for the higher temperatures and in the absence of NO, the major routes to the formation of $\mathrm{CO}$ are the reactions (5) and 6,

$$
\mathrm{HCCO}+\mathrm{O}_{2} \rightleftarrows 2 \mathrm{CO}+\mathrm{OH}
$$

while in the presence of $\mathrm{NO}$, the formation of $\mathrm{CO}$ for the higher temperatures occurs only through the reaction (5), because the HCCO radicals, instead of reacting to form $\mathrm{CO}$ (reaction (6)), react with NO to form HCN and, with minor importance, HCNO through the reactions (7) and (8), respectively. In this way, with the increase of temperature, the presence of NO diminishes the $\mathrm{CO}$ concentration formed, and shifts the maximum concentration of $\mathrm{CO}$ to higher temperatures for stoichiometric conditions.

$$
\begin{aligned}
& \mathrm{HCCO}+\mathrm{NO} \rightleftarrows \mathrm{HCN}+\mathrm{CO}_{2} \\
& \mathrm{HCCO}+\mathrm{NO} \rightleftarrows \mathrm{HCNO}+\mathrm{CO}
\end{aligned}
$$

For $\lambda=5$ and 50 (Fig. 5), the presence of NO modifies the onset of formation of CO, by shifting the onset of the consumption of 2-MF toward lower temperatures.

$\mathrm{CO}_{2}$ is formed for all the $\lambda$ values studied, both in the absence and in the presence of $\mathrm{NO}$, and its concentration increases with increasing temperature. For $\lambda=1,5$, and 50, the beginning of formation of $\mathrm{CO}_{2}$ coincides with the maximum of the $\mathrm{CO}$ concentration profile. Under these conditions, 2-MF is completely oxidized to $\mathrm{CO}_{2}$ at the highest temperature studied, whereas for $\lambda=0.3$, the lack of oxygen prevents complete oxidation of 2-MF.

Minor species, such as $\mathrm{C}_{2} \mathrm{H}_{4}$ and $\mathrm{C}_{2} \mathrm{H}_{2}$, were found in the experiments performed under very fuel-rich conditions. The concentration profiles of these species as a function of temperature are shown in Fig. 6. The $\mathrm{C}_{2} \mathrm{H}_{4}$ concentration profile shows a maximum, while with increasing temperature, increases $\mathrm{C}_{2} \mathrm{H}_{2}$ concentration. The model predicts the trend of experimental results for both $\mathrm{C}_{2} \mathrm{H}_{4}$ and $\mathrm{C}_{2} \mathrm{H}_{2}$, but does not fit well to them. The model underestimates the maximum concentration of $\mathrm{C}_{2} \mathrm{H}_{4}$, although for both experimental and modelling data, $\mathrm{C}_{2} \mathrm{H}_{4}$ peaks around $1273 \mathrm{~K}$. On the other hand, the model overestimates the $\mathrm{C}_{2} \mathrm{H}_{2}$ concentration.

Figure 7 shows the rate of production analysis at $50 \%$ 2-MF consumption for both in the absence and in the presence of NO. When NO is present, no appreciable differences have been found for the 2-MF reaction routes. However, NO is found to act by modifying the radical pool and thus favoring certain reactions over others.

Under very fuel-rich and stoichiometric conditions, the thermal decomposition of 2-MF involving carbene intermediates occurs to form 1-butyne $\left(\mathrm{CHCCH}_{2} \mathrm{CH}_{3}\right)$ and $\mathrm{CO}$ (pathway 1 ), or, only under very fuel-rich conditions, to form propargyl $\left(\mathrm{H}_{2} \mathrm{CCCH}\right)$ and acetyl $\left(\mathrm{CH}_{3} \mathrm{CO}\right)$ radicals (pathway 2$)$.

From $\lambda=0.3$ to $\lambda=5$, the $\mathrm{H}$-atom addition occurs at the $\mathrm{C} 5$ site of 2-MF to ultimately form vinyl ketene $\left(\mathrm{CH}_{2} \mathrm{CHCHCO}\right)$ and methyl radicals (pathway 3). $\mathrm{CH}_{2} \mathrm{CHCHCO}$ formed can be consumed by different reactions involving the $\mathrm{H} / \mathrm{O}$ radical pool, depending on the 


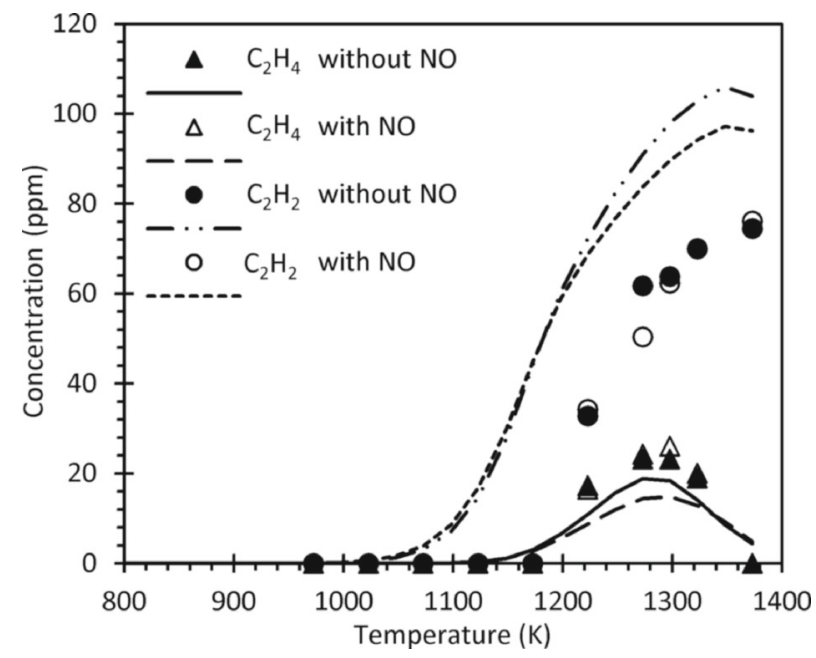

Fig. 6 Concentration profiles of the minor species, as a function of temperature, in the 2-MF oxidation for $\lambda=0.3$, at atmospheric pressure. Experimental data (symbols) and modelling predictions (lines)

oxygen present in the environment to give as principal path the formation of 2-methyl vinyl radical $\left(\mathrm{CH}_{3} \mathrm{CHCH}\right)$ and $\mathrm{CO}$ (reaction (9)), and with minor importance the formation of ketene $\left(\mathrm{CH}_{2} \mathrm{CO}\right)$, and ketenyl ( $\left.\mathrm{HCCO}\right)$ and $\mathrm{CH}_{2} \mathrm{HCO}$ radicals (reactions(10-13)),

$$
\begin{gathered}
\mathrm{CH}_{2} \mathrm{CHCHCO}+\mathrm{H} \rightleftarrows \mathrm{CH}_{3} \mathrm{CHCH}+\mathrm{CO} \\
\mathrm{CH}_{2} \mathrm{CHCHCO}+\mathrm{H} \rightleftarrows \mathrm{C}_{2} \mathrm{H}_{3}+\mathrm{CH}_{2} \mathrm{CO} \\
\mathrm{CH}_{2} \mathrm{CHCHCO}+\mathrm{H} \rightleftarrows \mathrm{C}_{2} \mathrm{H}_{4} \quad+\mathrm{HCCO} \\
\mathrm{CH}_{2} \mathrm{CHCHCO}+\mathrm{O} \rightleftarrows \mathrm{CH}_{2} \mathrm{HCO}+\mathrm{HCCO} \\
\mathrm{CH}_{2} \mathrm{CHCHCO}+\mathrm{O} \rightleftarrows 2 \mathrm{CH}_{2} \mathrm{CO}
\end{gathered}
$$

Under very fuel-rich and stoichiometric conditions, $\mathrm{CH}_{2} \mathrm{CHCHCO}$ is consumed through its reaction with $\mathrm{H}$ radicals, i.e, reactions (9-11). However, as the stoichiometry becomes leaner $(\lambda=5), \mathrm{CH}_{2} \mathrm{CHCHCO}$, in addition to react with $\mathrm{H}$ radicals, also reacts with $\mathrm{O}$ radicals through reactions (12) and (13). Later, and depending on the oxygen available and on the presence of $\mathrm{NO}$, ketene and $\mathrm{HCCO}$ radicals react with the $\mathrm{H} / \mathrm{OH}$ radical pool and molecular oxygen, respectively, being oxidized to $\mathrm{CO}$ and $\mathrm{CO}_{2}$ (reactions (14-19)), while $\mathrm{CH}_{2} \mathrm{HCO}$ radicals decompose thermally (reactions (20-22)),

$$
\begin{aligned}
& \mathrm{CH}_{2} \mathrm{CO}+\mathrm{H} \rightleftarrows \mathrm{CH}_{3}+\mathrm{CO} \\
& \mathrm{CH}_{2} \mathrm{CO}+\mathrm{OH} \rightleftarrows \mathrm{CH}_{2} \mathrm{OH}+\mathrm{CO} \\
& \mathrm{CH}_{2} \mathrm{CO}+\mathrm{OH} \rightleftarrows \mathrm{HCCO}+\mathrm{H}_{2} \mathrm{O} \\
& \mathrm{CH}_{2} \mathrm{CO}+\mathrm{OH} \rightleftarrows \mathrm{CH}_{3}+\mathrm{CO}_{2} \\
& \mathrm{HCCO}+\mathrm{O}_{2} \rightleftarrows 2 \mathrm{CO}+\mathrm{OH} \\
& \mathrm{HCCO}+\mathrm{O}_{2} \rightleftarrows \mathrm{CO}_{2}+\mathrm{CO}+\mathrm{H} \\
& \mathrm{CH}_{2} \mathrm{HCO}(+\mathrm{M}) \rightleftarrows \mathrm{CH}_{3}+\mathrm{CO}(+\mathrm{M}) \\
& \mathrm{CH}_{2} \mathrm{HCO} \rightleftarrows \mathrm{CH}_{3}+\mathrm{CO} \\
& \mathrm{CH}_{2} \mathrm{HCO}(+\mathrm{M}) \rightleftarrows \mathrm{CH}_{2} \mathrm{CO}+\mathrm{H}(+\mathrm{M})
\end{aligned}
$$




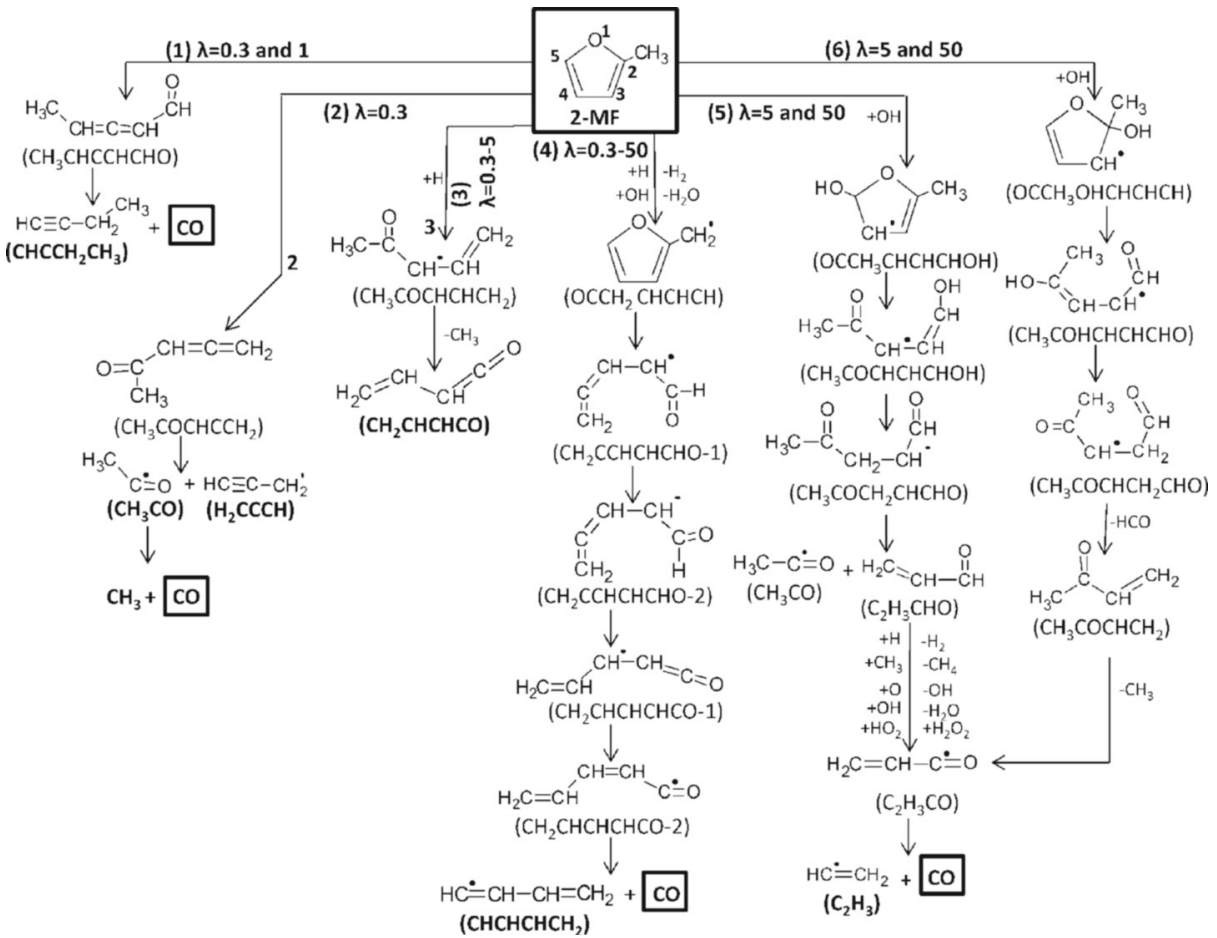

Fig. 7 Rate of production analysis for 2-MF oxidation both in the absence and in the presence of NO, carried out under at approximately $50 \%$ 2-MF consumption

Ketene consumption occurs in the same way both in the absence and in the presence of NO, but is affected by the availability of oxygen. Under stoichiometric and fuel-lean conditions, the ketene consumption occurs through (14-17) reactions, while under very fuel-rich conditions, the ketene consumption occurs only through r14 and r15 reactions. Regarding the HCCO consumption, it occurs in one way or another depending on whether NO is present or not. In the absence of NO, HCCO reacts with molecular oxygen (reactions (18) and 19)) for all the stoichiometries studied, but when NO is present, HCCO also interacts with NO. Then, in the presence of NO, for very fuel-rich and stoichiometric conditions, HCCO consumption is no longer given by reactions (18) and (19), but instead HCCO reacts with NO mainly through reactions (7) and (8). On the other hand, under fuel-lean conditions, the increase in oxygen concentration allows $\mathrm{HCCO}$ to interact both with NO and molecular oxygen (reactions (7), (8), (18) and (19)). Finally, $\mathrm{CH}_{2} \mathrm{HCO}$ radicals, which are formed only under fuel-lean $(\lambda=5)$ conditions as it has been mentioned earlier, are consumed by thermal decomposition (reactions (20-22)) both in the absence and in the presence of NO.

For all $\lambda$ values, $\lambda=0.3-50$, the $\mathrm{H}$-abstraction from the methyl group of 2-MF by $\mathrm{H}$ (principally for $\lambda=0.3$ and 1 ) and $\mathrm{OH}$ radicals (principally for $\lambda=5$ and 50) (pathway 4) to give as an intermediate product the resonance-stabilized 2-methylfuranyl radicals $\left(\mathrm{OCCH}_{2} \mathrm{CHCHCH}\right)$ occurs. Thus, ring opening via cleavage of the $\mathrm{C}-\mathrm{O}$ bond results to finally yield n-butadienyl radicals $\left(\mathrm{CHCHCHCH}_{2}\right)$ and $\mathrm{CO}$. The $\mathrm{CHCHCHCH}_{2}$ radicals formed by this path react with oxygen (reaction (23)) promoting the formation of $\mathrm{HO}_{2}$ radicals (reaction (24)), which are involved in the $\mathrm{NO}-\mathrm{NO}_{2}$ interconversion (reactions (25) and 


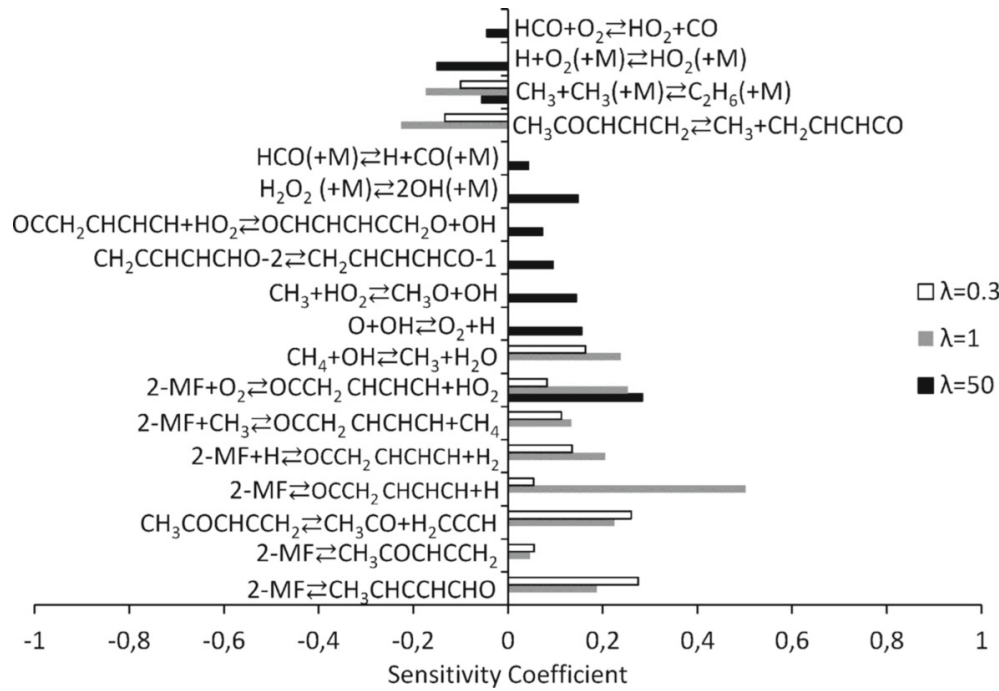

Fig. 8 Sensitivity analysis for 2-MF oxidation in the absence of NO (sets 1, 3, and 7 in Table 1, at 1048, 1048 , and $923 \mathrm{~K}$, respectively)

(26)) resulting in an increase of $\mathrm{OH}$ radicals production, which are the main responsible for 2-MF consumption under fuel-lean and very fuel-lean conditions. Because of this, in the presence of $\mathrm{NO}$ and for $\lambda=5$ and 50 , the 2-MF oxidation beings to occur at lower temperatures as the stoichiometry becomes leaner, as can be seen in Fig. 5.

$$
\begin{gathered}
\mathrm{CHCHCHCH}_{2}+\mathrm{O}_{2} \rightleftarrows \mathrm{C}_{2} \mathrm{H}_{3} \mathrm{CHO}+\mathrm{HCO} \\
\mathrm{HCO}+\mathrm{O}_{2} \rightleftarrows \mathrm{HO}_{2}+\mathrm{CO} \\
\mathrm{NO}+\mathrm{HO}_{2} \rightleftarrows \mathrm{NO}_{2}+\mathrm{OH} \\
\mathrm{NO}_{2}+\mathrm{H} \rightleftarrows \mathrm{NO}+\mathrm{OH}
\end{gathered}
$$

Other important paths for the 2-MF consumption, for $\lambda=5$ and 50 , are the $\mathrm{OH}$-addition at the $\mathrm{C} 5$ (pathway 5) and at the $\mathrm{C} 2$ (pathway 6) sites of 2-MF to form acroleine $\left(\mathrm{C}_{2} \mathrm{H}_{3} \mathrm{CHO}\right.$ ) and methyl vinyl ketone $\left(\mathrm{CH}_{3} \mathrm{COCHCH}_{2}\right)$, respectively, both products culminating in the formation of vinyl radicals $\left(\mathrm{C}_{2} \mathrm{H}_{3}\right)$ and $\mathrm{CO}$. The $\mathrm{OH}$-addition process has been mentioned by Wei et al. [14] as reactions that contribute very little to 2-MF consumption, while in the work of Uygun et al. [15] it is mentioned that 2-MF is mainly consumed by the OH-addition at $\mathrm{C} 5$ and at $\mathrm{C} 2$ sites of 2-MF under their experimental conditions.

The $\mathrm{H}$-addition at the $\mathrm{C} 2$ site of 2-MF to form furan and methyl radicals has been identified in the work of Tran et al. [22] as an important path for the consumption of 2-MF. However, in the rate of production analysis made in Fig. 7, this path does not appear as a principal path for the 2-MF consumption. This could be due to the fact that the submechanism for 2-MF from Somers et al. [20] used in the present calculations includes the reaction of the $\mathrm{H}$-addition at the $\mathrm{C} 5$ site of 2-MF to lead to the formation of vinyl ketene $\left(\mathrm{CH}_{2} \mathrm{CHCHCO}\right)$, which has been detected experimentally in the work of Moshammer et al. [26] on the combustion chemistry of 2-MF.

Figures 8 and 9 present sensitivity coefficients obtained through a first-order sensitivity analysis of $\mathrm{CO}$ at the temperature at which 2-MF starts to be consumed for both in the absence (sets 1, 3 and 7 in Table 1) and in the presence of NO (sets 2, 4 and 8 in Table 1), 
respectively. The sensitivity coefficients are calculated as $\mathrm{S}=\delta \mathrm{Y}_{\mathrm{j}} / \delta \mathrm{A}_{\mathrm{i}}$, where $\mathrm{Y}_{\mathrm{j}}$ is the mass fraction of the $j$ th species and $\mathrm{A}_{\mathrm{i}}$ is the pre-exponential constant for reaction $i$ [38]. Positive coefficients correspond to reactions which promote reactivity and vice versa.

It can be seen in Figs. 8 and 9 that the reactions to which the 2-MF conversion is more sensitive depend on the oxygen concentration and on the presence of NO. Both in the absence and in the presence of NO, the 2-MF conversion is more sensitive to the reactions involving the 2-MF thermal decomposition and the thermal decomposition of its intermediates $\left(\mathrm{CH}_{3} \mathrm{COCHCCH}_{2}, \mathrm{CH}_{2} \mathrm{CCHCHCHO}-2\right.$, and $\left.\mathrm{CH}_{3} \mathrm{COCHCHCH}_{2}\right)$. Another important reaction in the conversion process of $2-\mathrm{MF}$, both in the absence and in the presence of $\mathrm{NO}$, is the $\mathrm{H}$-abstraction from the methyl side ( $\mathrm{C} 2$ site) in 2-MF by small species $\left(\mathrm{H}\right.$ and $\left.\mathrm{O}_{2}\right)$ to give the 2-methylfuranyl radical $\left(\mathrm{OCCH}_{2} \mathrm{CHCHCH}\right)$. The chain-branching reaction (27),

$$
\mathrm{O}+\mathrm{OH} \rightleftarrows \mathrm{O}_{2}+\mathrm{H}
$$

also appears to influence the 2-MF conversion, both in the absence and in the presence of NO. The interactions between methane with $\mathrm{OH}$ radicals, molecular oxygen with $\mathrm{H}$ radicals, and the reaction of recombination of methyl radicals also appear to be important.

In the absence of $\mathrm{NO}$, other reactions to which the 2-MF conversion is sensitive include: 1) the 2-MF interaction with methyl radicals, 2) the reaction between 2-methylfuranyl radicals and $\mathrm{HO}_{2}$, and 3) the formation of $\mathrm{HO}_{2}$, and $\mathrm{H}$ and $\mathrm{OH}$ radicals through reactions (5), (24) and those involving the hydrogen peroxide decomposition, and the interaction of methyl radicals with $\mathrm{HO}_{2}$.

On the other hand, in the presence of NO, the reactions: 1) H-abstraction from the methyl side in 2-MF by $\mathrm{OH}$ radicals, and 2) methyl radicals with $\mathrm{NO}$, also appear to be important for the 2-MF conversion. Furthermore, the decomposition of the $\mathrm{CH}_{3} \mathrm{COCHCHCHOH}$, and $\mathrm{CH}_{3} \mathrm{COHCHCHCHO}$ intermediates appear also as sensitive reactions.

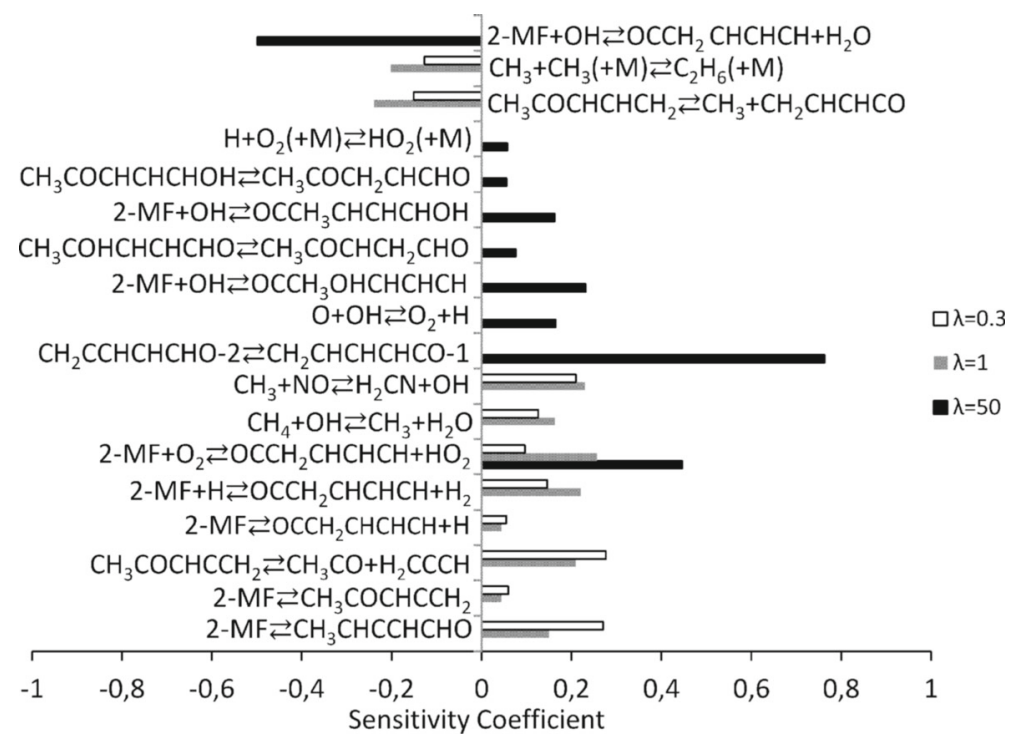

Fig. 9 Sensitivity analysis for 2-MF oxidation in the presence of NO (sets 2, 4, and 8 in Table 1, at 1048, 1048 , and $873 \mathrm{~K}$, respectively) 
Having analyzed the influence of the oxygen concentration and the presence of NO on the 2-MF oxidation, the capacity of 2-MF to reduce the NO concentration in the different environments studied will be now discussed. Figure 10 shows the experimental data and the modelling calculations of the NO concentration profile as a function of temperature for all $\lambda$ values studied. For $\lambda=0.3$ and 1 (upper part of the Fig. 10), it is seen that with the increase of temperature, the NO concentration decreases slightly, while for $\lambda=5$ and 50 (lower part of the Fig. 10), a minimum in the NO concentration profile is observed, which is more noticeable for $\lambda=50$.

Figure 11 shows the reaction path diagram for the NO consumption. For $\lambda=0.3$ and 1, the reaction of $\mathrm{NO}$ with $\mathrm{C}_{2} \mathrm{H}_{3}$ radicals to give $\mathrm{HNO}$ is an important via for the NO consumption. Also, the reaction of $\mathrm{NO}$ with $\mathrm{HCCO}$ radicals to give $\mathrm{HCN}$ (reaction (7)), and with $\mathrm{CH}_{3}$ radicals, to give $\mathrm{HCN}$ and $\mathrm{H}_{2} \mathrm{CN}$, are important routes for the NO consumption.
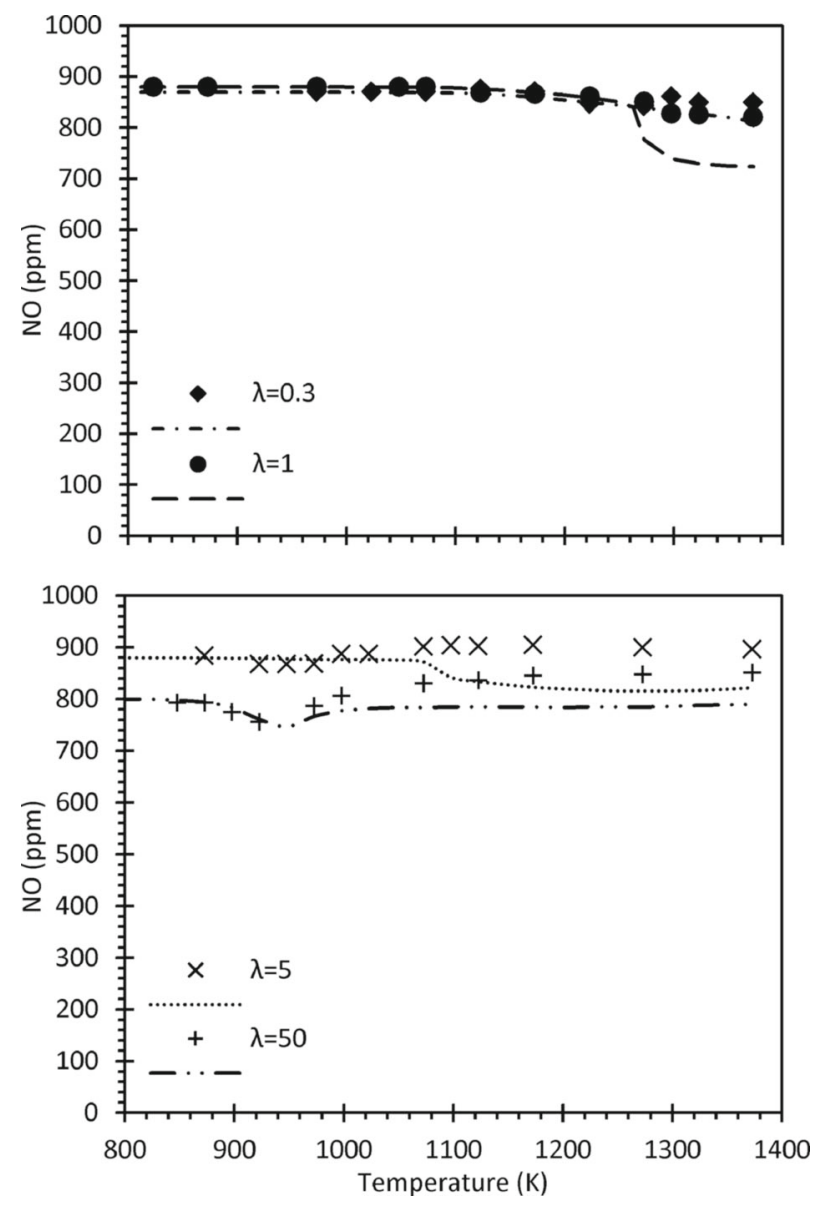

Fig. 10 Concentration profile of NO, as a function of temperature, for $\lambda=0.3,1$ (top), 5 and 50 (bottom), at atmospheric pressure. Experimental data (symbols) and modelling predictions (lines) 
Besides these paths another route for $\mathrm{NO}$ copsumption from stoichiometric to very fuelfuel-lean and very fuel-lean conditions the reaction between $\mathrm{NO}$ and $\mathrm{CH}_{3} \mathrm{O}_{2}$ radicals to give $\mathrm{NO}_{2}$ can occur.

For both $\lambda=0.3$ and 1 , the main path for $\mathrm{NO}$ consumption involves the sequence: $\mathrm{NO} \rightarrow \mathrm{HCN} \rightarrow \mathrm{CH}_{3} \mathrm{CN} \rightarrow \mathrm{CH}_{2} \mathrm{CN} \rightarrow \mathrm{CN} \rightarrow \mathrm{NCO} \rightarrow \mathrm{N}_{2} / \mathrm{N}_{2} \mathrm{O}$. For $\lambda=0.3$ and $1, \mathrm{~N}_{2} \mathrm{O}$ forms $\mathrm{NO}$ by reaction with $\mathrm{H}$ radicals, and for $\lambda=0.3$ also $\mathrm{N}_{2} \mathrm{O}$ decomposes to $\mathrm{N}_{2}$. However, for $\lambda=0.3$ and 1 , the main path for the consumption of $\mathrm{NCO}$ is its reaction with $\mathrm{NO}$ to give $\mathrm{N}_{2}$. In this way, under very fuel-rich and stoichiometric conditions, $\mathrm{NO}$ is reduced basically by reburn reactions $[27,39]$.

With the increase of the oxygen concentration $(\lambda=5$ and 50), the most important reaction for $\mathrm{NO}$ consumption is the reaction of $\mathrm{NO}$ with $\mathrm{HO}_{2}$ to form $\mathrm{NO}_{2}$ and $\mathrm{OH}$ radicals (reaction (25)). In this way, the minimum observed in the Fig. 10 could be due to the NO$\mathrm{NO}_{2}$ interconversion which occurs through the reaction of $\mathrm{NO}_{2}$ with $\mathrm{CH}_{3}$ and $\mathrm{H}$ radicals to give back NO. This interconversion limits a net reduction of NO.

The mechanism compiled in this work has also been used to simulate the ignition delay times measured by Wei et al. [14]. As an example, Fig. 12 shows the experimental and modelling calculation results for the operating conditions: $\varphi=1,2-\mathrm{MF}=1 \%, \mathrm{O}_{2}=6$, $\mathrm{Ar}=93 \%, \mathrm{P}=1.25,4.25$, and $10.65 \mathrm{bar}$. The simulations for other conditions can be seen in Figs. S8-S12 in Online Resource. Results obtained reveal that the mechanism captures also with good accuracy the ignition behavior of 2-MF for the different mixtures and the different pressures evaluated.

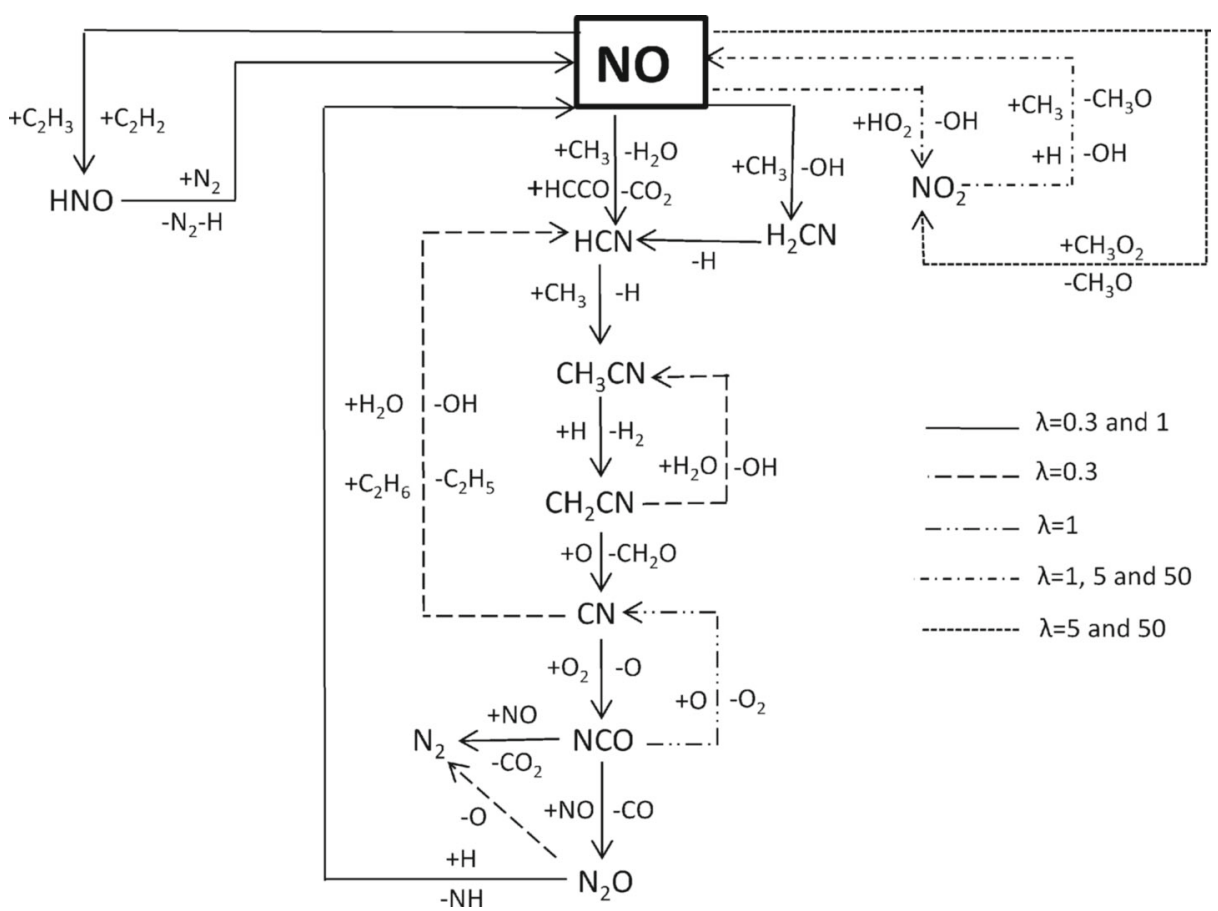

Fig. 11 Reaction path diagram for the NO consumption, for $\lambda=0.3,1,5$ and 50 


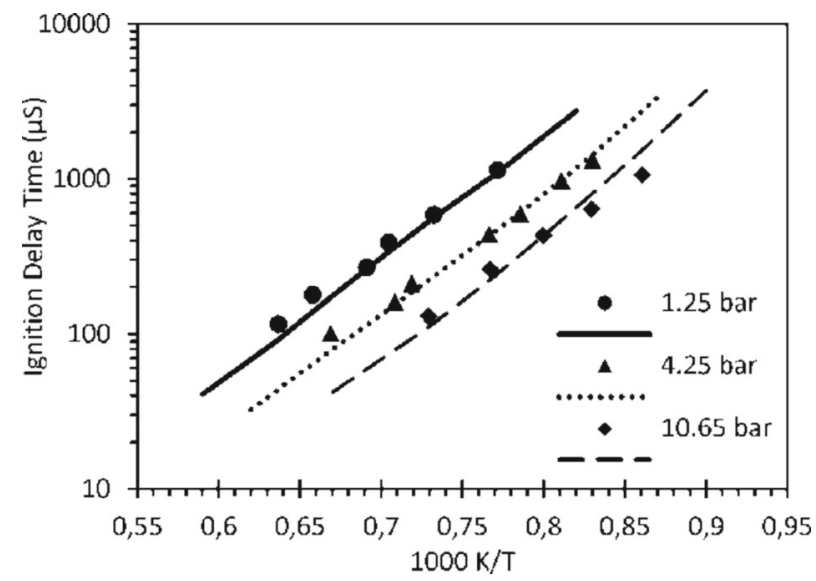

Fig. 12 Experimental ignition delay times (symbols) and modelling predictions (lines), for $\varphi=1(\lambda=1)$, $2-\mathrm{MF}=1 \%, \mathrm{O}_{2}=6 \%, \mathrm{Ar}=93 \%$, at $1.25,4.25$, and $10.65 \mathrm{bar}$

\section{Conclusions}

A study of 2-methylfuran oxidation has been performed in a flow reactor installation at different temperatures and air excess ratio values. The experiments have been also performed in the presence of $900 \mathrm{ppm}$ of NO. In this way, the influence of the stoichiometry, and the presence of $\mathrm{NO}$ on the 2-MF oxidation, as well as the capacity of 2-MF to reduce the NO concentration at different stoichiometries, have been studied. Modelling calculations using three different reaction sub-mechanisms for 2-MF conversion incorporated to a base model, have been compared with the experimental data. In general, the three sub-mechanisms for 2-MF conversion reproduce reasonably well the experimental trends, but best results begin observed using the mechanism that incorporates the 2-MF sub-mechanism by Somers et al. [20], even though this model fails to predict the experimental data for $\lambda=5$ in the presence of NO, and for $\lambda=50$ in the absence of NO.

The results of performing both, rate of production and sensitivity analysis indicate that: 1) for very fuel-rich and stoichiometric conditions, the temperature for the onset for the conversion of 2-MF remains the same because the thermal decomposition of 2-MF appears to be the main conversion pathway. On the other hand, under fuel-lean and very fuel-lean conditions, the onset for the 2-MF consumption is shifted to lower temperatures as the oxygen concentration increases, because its reaction with $\mathrm{OH}$ radicals appears to be the main responsible for the 2-MF consumption, 2) the 2-MF reaction routes appear to be the same, for both in the absence and in the presence of NO. However, NO is found to act by modifying the radical pool and thus favors certain reactions over others. Thus, for fuel-lean and very fuel-lean conditions, when NO is present, the displacement of the onset for the 2-MF consumption to lower temperatures is greater because the formation of $\mathrm{OH}$ radicals is more favored than in the absence of NO, 3) under very fuel-rich and stoichiometric conditions the presence of $\mathrm{NO}$ does not affect the onset of formation products as $\mathrm{CO}$, but diminishes the concentration at higher temperatures due to the occurrence of competing reactions, and 4) when $\mathrm{NO}$ is added, it is converted to $\mathrm{N}_{2}$ by reaction with $\mathrm{HCCO}$ and $\mathrm{CH}_{3}$ radicals (reburn reactions) under very fuel-rich and stoichiometric conditions, while under fuel-lean and very-fuel lean conditions, the $\mathrm{NO}-\mathrm{NO}_{2}$ interconversion is the dominant step. 
Acknowledgments The authors express their gratitude to the Aragón Government (GPT group) and to MINECO and FEDER (Project CTQ2012-34423), for financial support. Ms. K. Alexandrino acknowledges to MINECO for the pre-doctoral grant awarded (BES-2013-063049).

Compliance to Ethical Standard This manuscript has not been published and is not under consideration for publication elsewhere. However, this same manuscript, with some additional changes, was presented in the SPEIC2014 meeting, held in Lisbon, from 19-21 November 2014. The organizing committee of this meeting offered us to submit this manuscript to the SPEIC2014 Special Issue of Flow, Turbulence and Combustion.

Consent to submit the manuscript has been received from all co-authors. We have no conflicts of interest to disclose.

\section{References}

1. Román-Leshkov, Y., Barret, C.J., Liu, Z.Y., Dumesic, J.A.: Production of dimethylfuran for liquid fuels from biomass-derived carbohydrates. Nature 447, 982-985 (2007)

2. Zhao, H., Holladay, J.E., Brown, H., Zhang, Z.C.: Metal chlorides in ionic liquid solvents convert sugars to 5-hydroxymethylfurfural. Science 316, 1597-1600 (2007)

3. Mascal, M., Nikitin, E.B.: Direct high-yield conversion of cellulose into biofuel. Angew. Chem. 47, 7924-7926 (2008)

4. Alexandrino, K., Millera, A., Bilbao, R., Alzueta, M.U.: Interaction between 2,5-dimethylfuran and nitric oxide: experimental and modeling study. Energy Fuels 28, 4193-4198 (2014)

5. Alexandrino, K., Millera, A., Bilbao, R., Alzueta, M.U.: Novel aspects in the pyrolysis and oxidation of 2,5-dimethylfuran. Proc. Combust. Inst. 35, 1717-1725 (2015)

6. Thewes, M., Muether, M., Pischinger, S., Budde, M., Brunn, A., Sehr, A., Adomeit, P., Klankermayer, J.: Analysis of the impact of 2-methylfuran on mixture formation and combustion in a direct-injection spark-iginition engine. Energy Fuels 25, 5549-5561 (2011)

7. Pan, M., Shu, G., Pan, J., Wei, H., Feng, D., Guo, Y., Liang, Y.: Performance comparison of 2methylfuran and gasoline on a spark-ignition engine with cooled exhaust gas recirculation. Fuel 132, $36-43(2014)$

8. Wang, C., Xu, H., Daniel, R., Ghafourian, A., Herreros, J.M., Shuai, S., Ma, X.: Combustion characteristics and emissions of 2-methylfuran compared to 2,5-dimethylfuran, gasoline and ethanol in a DISI engine. Fuel 103, 200-211 (2013)

9. Grela, M.A., Amorebieta, V.T., Colussi, A.J.: Very low pressure pyrolysis of furan, 2-methylfuran, and 2,5-dimethylfuran. The stability of the furan ring. J. Phys. Chem. 89, 38-41 (1985)

10. Lifshitz, A., Tamburu, C., Shashua, R.: Decomposition of 2-methylfuran. Experimental and modeling study. J. Phys. Chem. A 101, 1018-1029 (1997)

11. Wei, L., Li, Z., Tong, L., Wang, Z., Jin, H., Yao, M., Zheng, Z., Wang, C., Xu, H.: Primary combustion intermediates in lean and rich low-pressure premixed laminar 2-methylfuran/oxygen/argon flames. Energy Fuels 26, 6651-6660 (2012)

12. Ma, X., Jiang, C., Xu, H., Shuai, S., Ding, H.: Laminar burning characteristics of 2-methylfuran compared with 2,5-dimethylfuran and isooctane. Energy Fuels 27, 6212-6221 (2013)

13. Ma, X., Jiang, C., Xu, H., Ding, H., Shuai, S.: Laminar burning characteristics of 2-methylfuran and isooctane blend fuels. Fuel 116, 281-291 (2014)

14. Wei, L., Tang, C., Man, X., Huang, Z.: Shock-tube experiments and kinetic modeling of 2-methylfuran ignition at elevated pressure. Energy Fuels 27, 7809-7816 (2013)

15. Uygun, Y., Ishihara, S., Olivier, H.: A high pressure ignition delay time study of 2-methylfuran and tetrahydrofuran in shock tubes. Combust. Flame 161, 2519-2530 (2014)

16. Eldeeb, M.A., Akih-Kumgeh, B.: Reactivity trends in furan and alkyl furan combustion. Energy Fuels 28, 6618-6626 (2014)

17. Xu, N., Tang, C., Meng, X., Fan, X., Tian, Z., Huang, Z.: Experimental and kinetic study on the ignition delay times of 2,5-dimethylfuran and the comparison to 2-methylfuran and furan, Energy Fuels, doi:10.1021/acs.energyfuels.5b00906 (2015)

18. Davis, A.C., Sarathy, S.M.: Computational study of the combustion and atmospheric decomposition of 2-methylfuran. J. Phys. Chem. A 117, 7670-7685 (2013)

19. Somers, K.P., Simmie, J.M., Gillespie, F., Burke, U., Connolly, J., Metcalfe, W.K., Battin-Leclerc, F., Dirrenberger, P., Herbinet, O., Glaude, P.-A., Curran, H.J.: A high temperature and atmospheric pressure 
experimental and detailed chemical kinetic modelling study of 2-methyl furan oxidation. Proc. Combust. Inst. 34, 225-232 (2013)

20. Somers, K., Simmie, J., Metcalfe, W., Curran, H.: The pyrolysis of 2-MF: a quantum chemical, statistical rate theory and kinetic modeling study. Phys. Chem. Chem. Phys. 16, 5349-5367 (2014)

21. Liu, D., Togbé, C., Tran, L.S., Felsmann, D., Oßwald, P., Nau, P., Koppmann, J., Lackner, A., Glaude, P.A., Sirjean, B., Fournet, R., Battin-Leclerc, F., Kohse-Höinghaus, K.: Combustion chemistry and flame structure of furan group using molecular-beam mass spectrometry and gas chromatography-Part I: Furan. Combust. Flame 161, 748-765 (2014)

22. Tran, L.S., Togbé, C., Liu, D., Felsmann, D., Oßwald, P., Glaude, P.-A., Fournet, R., Sirjean, B., BattinLeclerc, F., Kohse-Höinghaus, K.: Combustion chemistry and ?ame structure of furan group biofuels using molecular-beam mass spectrometry and gas chromatography-Part II: 2-methylfuran. Combust. Flame 161, 766-779 (2014)

23. Togbé, C., Tran, L.S., Liu, D., Felsmann, D., Oßwald, P., Glaude, P.A., Sirjean, B., Fournet, R., BattinLeclerc, F., Kohse-Höinghaus, K.: Combustion chemistry and flame structure of furan group using molecular-beam mass spectrometry and gas chromatography-Part III: 2,5-dimethylfuran. Combust. Flame 161, 780-797 (2014)

24. Sirjean, B., Fournet, R., Glaude, P.A., Battin-Leclerc, F., Wang, W., Oehlschlaeger, M.A.: Shock tube and chemical kinetic modeling study of the oxidation of 2,5-dimethylfuran. J. Phys. Chem. A. 117, 1371-1392 (2013)

25. Tian, Z., Yuan, T., Fournet, R., Glaude, P.A., Sirjean, B., Battin-Leclerc, F., Zhang, K., Qi, F.: An experimental and kinetic investigation of premixed furan/oxygen/flames. Combust. Flame 158, 756-773 (2011)

26. Moshammer, K., Lucassen, A., Togbé, C., Kohse-Höinghaus, K., Hansen, N.: Formation of oxygenated and hydrocarbon intermediates in premixed combustion of 2-methylfuran. Z. Phys. Chem. 229, 507-528 (2015)

27. Glarborg, P., Alzueta, M.U., Dam-Johansen, K., Miller, J.A.: Kinetic modeling of hydrocarbon nitric oxide interactions in a flow reactor. Combust. Flame 115, 1-27 (1998)

28. Abián, M., Silva, S.L., Millera, A., Bilbao, R., Alzueta, M.U.: Effect of operating conditions on NO reduction by acetylene-ethanol mixtures. Fuel Process Technol. 91, 1204-1211 (2010)

29. Kristensen, P.G., Glarborg, P., Dam-Johansen, K.: Nitrogen chemistry during burnout in fuel-staged combustion. Combust. Flame 107, 211-222 (1996)

30. Yanfeng, G., Shenghua, L., Hejun, G., Tiegang, H., Longbao, Z.: A new diesel oxygenate additive and its effects on engine combustion and emissions. Appl. Therm. Eng. 27, 202-207 (2007)

31. Yao, C., Cheung, C.S., Cheng, C., Wang, Y., Chan, T.L., Lee, S.C.: Effect of Diesel/methanol compound combustion on Diesel engine combustion and emissions. Energ. Convers. Manag. 49, 1696-1704 (2008)

32. Alzueta, M.U., Finestra, M., Bilbao, R.: Methanol oxidation and its interaction with nitrogen oxide. Energy Fuels 15, 724-729 (2001)

33. Alzueta, M.U., Hernández, J.M.: Ethanol oxidation and its interaction with nitric oxide. Energy Fuels 16, 166-171 (2002)

34. Glarborg, P., Alzueta, M.U., Kjaergaard, K., Dam-Johansen, K.: Oxidation of formaldehyde and its interaction with nitric oxide in a flow reactor. Combust. Flame 132, 629-638 (2003)

35. Alzueta, M.U., Borruey, M., Callejas, M.A., Millera, A., Bilbao, R.: An experimental and modeling study of the oxidation of acetylene in a flow reactor. Combust. Flame 152, 377-386 (2008)

36. Alzueta, M.U., Aranda, V., Monge, F., Millera, A., Bilbao, R.: Oxidation of methyl formate and its interaction with nitric oxide. Combust. Flame 160, 853-860 (2013)

37. Kee, R.J., Rupley, F.M., Miller, J.A.: Chemkin-II: A fortran chemical kinetics package for the analysis of gas-phase chemical kinetics, Sandia National Laboratories. SAND89-8009B (1989)

38. CHEMKIN-PRO 15131, Reaction Design, San Diego (2013)

39. Bilbao, R., Alzueta, M.U., Millera, A.: Experimental study of the influence of the operating variables on natural gas reburning efficiency. Ind. Eng. Chem. Res. 34, 4531-4539 (1995) 